\title{
A SUPERVISÃO DOS ESTÁGIOS DE ENSINO PELOS PROFESSORES DA EDUCAÇÃO BÁSICA: LIMITAÇÕES E DESAFIOS
}

Dimair Souza França

Universidade Federal de Mato Grosso do Sul

\section{Resumo}

O propósito deste texto é discutir o processo de supervisão de estágio realizado pelos professores da educação básica junto aos alunos dos cursos de formação de professores através da análise do papel do professor formador, bem como evidenciar a importância da tarefa realizada por esses profissionais que recebem e acompanham os alunos estagiários em suas inserções pela escola e pela sala de aula. À medida que novos conhecimentos sobre essa atividade forem trazidos para o debate, será possível evidenciar a importância do processo de constituição do ofício de ensinar, por se constituir no objeto de trabalho de professores e futuros professores que ocorre no contexto da organização escolar e se desenvolve de forma singular, mas não menos determinado pelas condições históricas dadas: possibilidades concretas do exercício da docência, condições de trabalho e salário, adversidades, limitações e desafios postos pela realidade social e educacional.

Palavras-chave: Estágio Curricular; Professor Formador; Formação de Professores. 


\title{
THE SUPERVISION OF TEACHING PRACTICE BY TEACHERS OF BASIC EDUCATION: LIMITATIONS AND CHALLENGES
}

\begin{abstract}
The paper aims to discuss the process of basic education teachers supervising teacher practice activities developed by the students of teacher training courses, by means of analyzing the role of the teacher trainer, as well as to highlight the importance of the task carried out by the professionals who receive and monitor the students in their insertions at the school and in the classroom. As new knowledge about the activity is brought to the debate, it will be possible to highlight the importance of building the teaching work, as it is the object of work of teachers and future teachers that is developed within the context of the school organization, in a unique way, but also determined by historical conditions: concrete possibilities of exercising teaching, working conditions and salary, adversities, limitations and challenges posed by the social and educational reality.
\end{abstract}

Keywords: Curricular Practical Training; Teacher Trainer; Teacher Training. 


\section{Introdução}

Este trabalho tem como objetivo discutir o processo de supervisão de estágio realizado pelos professores da educação básica junto aos alunos estagiários, futuros professores, a partir do contato com a realidade da escola e da sala de aula. Para tanto, será apresentada inicialmente uma breve revisão sobre o estágio na formação dos futuros professores para, a seguir, discutir as limitações e desafios que estão postos hoje na realização desta atividade no interior das escolas de educação básica.

A finalidade é mostrar a sua importância no processo de constituição da docência, pois o professor da escola básica (professor formador) tem uma tarefa relevante a desempenhar junto aos alunos estagiários ao favorecer o contato com as crianças, com o fazer docente, com os limites e possibilidades de uma sala de aula. Nesta discussão o propósito é evidenciar a importância da qualidade da supervisão efetivada pelos professores que recebem e acompanham os alunos estagiários em suas inserções pela sala de aula.

Tal qual assinala Almeida (1994), é preciso haver intenção por parte destes profissionais das escolas campo de estágio no sentido da coresponsabilização pela formação dos futuros professores que irão atuar na escola pública e querer introduzir esses alunos estagiários na vivência da prática docente, possibilitando o contato e a apropriação dos saberes socialmente elaborados sobre o fazer docente.

Os estágios de ensino e a escola básica: novas e velhas práticas na preparação dos futuros professores

A formação prática do futuro professor esteve vinculada à formação pedagógica, cujas matrizes encontram-se na escola fundamental, o antigo primário. De acordo com Pimenta (1994), a questão da prática sempre esteve presente desde as primeiras escolas normais, sendo que esta poderia ser explícita, sob a forma de disciplina, ou implícita, sob a forma de recomendação, orientação, entre outros.

Olh@ res, Guarulhos, v. 1, n1, p. 64-89, maio. 2013. 
Entretanto, foi o Parecer 292/1962 que, ao tratar da formação pedagógica para a licenciatura em geral, estabeleceu a obrigatoriedade da Prática de Ensino como componente curricular dos cursos de Licenciatura e de Pedagogia, indicando que a mesma deveria ser feita nas próprias escolas da comunidade, sob a forma de estágio supervisionado, onde o futuro professor fosse assistido por professores especialmente designados para orientá-lo. Ainda de acordo com este Parecer, a Prática de Ensino deveria possibilitar aos futuros mestres as condições para "[...] aplicar os conhecimentos adquiridos, dentro das possibilidades e limitações de uma escola real, e ter vivência do ato docente em seu tríplice aspecto de planejamento, execução e verificação" (BRASIL, 1962, p. 98, grifo do autor).

Ao estabelecer a obrigatoriedade da Prática de Ensino para as Licenciaturas e para o curso de Pedagogia, este Parecer definiu, além da forma a ser adotada e do local de sua realização, a duração de um semestre letivo para este componente curricular. As escolas da comunidade tornaram-se, oficialmente, o espaço de realização desta atividade, devendo, portanto, oferecer condições para que o futuro professor pudesse trazer para a discussão a sua própria experiência e, ao mesmo tempo, assinalava que o estágio, se considerado um serviço de extensão, poderia contribuir para a renovação dos padrões escolares do meio (BRASIL, 1962).

Nesta reformulação atribuiu-se às escolas a responsabilidade na formação dos futuros professores, cuja tarefa, incumbida a profissionais especialmente designados para orientar o futuro professor, restringia-se à aplicação dos conhecimentos adquiridos no curso e ao planejamento, execução e avaliação do ato docente (regência). Neste sentido, tem-se, desde então, um modelo de estágio que vai perdurar por muito tempo na formação de professores, além de imputar à escola e ao professor mais uma tarefa, entre tantas outras.

Durante muito tempo prevaleceu esse modelo de estágio, configurando-se como um momento crítico da formação dos futuros professores. Estes deveriam, num curto espaço de tempo, conhecer o trabalho do professor e desempenhar atividades inerentes a este trabalho em uma sala de aula sem, contudo, ter condições de aprofundar suas reflexões acerca daquela

Olh@ res, Guarulhos, v. 1, n1, p. 64-89, maio. 2013. 
realidade, dado o tempo e o espaço que dispunham para a sua realização. Esta situação acarretava muitas críticas em função do olhar aligeirado dos alunos, quase sempre carregados de juízos e valores construídos fora do contexto do curso de formação ou mesmo acirrados durante o processo formativo, não favorecendo a apropriação do saber fazer docente.

Ainda hoje, a formação prática dos futuros professores apresenta-se como uma questão menor no contexto dos cursos de formação de professores. Essa limitação pode ter origem nos modelos de formação adotados em nossa realidade que separam a fundamentação teórica e a formação profissionalizante nos currículos em decorrência da racionalidade técnica que tem prevalecido nesses cursos.

Segundo Monteiro (2000, p. 129), no modelo da racionalidade técnica “[...] o professor era considerado um técnico, cuja atividade profissional consistia na aplicação rigorosa de técnicas cientificamente fundamentadas". Ao professor era reservado um papel previamente estabelecido, na forma de habilidades e competências a dominar, que se manifestavam na aplicação eficaz de técnicas e estratégias às situações de ensino. Para a autora, "“[...] a preocupação maior era com a sala de aula, o 'manejo de classe', a capacidade de transmitir conhecimentos, escolher e utilizar as técnicas e recursos pertinentes, avaliar segundo os parâmetros adequados" (op. cit., p. 132).

Neste sentido, a autora assinala que a atividade prática necessita avançar no sentido de possibilitar que essa experiência seja entendida como construção, ou seja, "[...] uma situação em que o sujeito possui estruturas teóricas prévias para orientar a observação de algo - no caso a aula, considerada não como algo que está dado e, sim, algo que pode ser entendido e interpretado de diferentes maneiras" (MONTEIRO, 2000, p. 134), em contraposição ao modelo adotado, de acordo com orientações previamente definidas, de observação das boas práticas de ensino onde as aulas dadas, com suas técnicas e recursos, são objetos de atenção para posterior reprodução pelo futuro professor.

Por isso, o estágio requer uma clara significação acerca do que é ser professor para os atores envolvidos no processo de ensino, além do

Olh@ res, Guarulhos, v. 1, n1, p. 64-89, maio. 2013. 
envolvimento com a escola onde se efetiva esta atividade. Sem essas condições corre-se o risco de adotar modelos que irão contribuir muito pouco para com a construção de propostas comprometidas com um ensino de qualidade para todos.

É importante frisar que não se pretende propor uma inversão no currículo de formação, sinalizando para uma ênfase excessiva na prática. O estágio é compreendido aqui como uma atividade de caráter teórico-prático, tal como assinala Pimenta (1994, p. 185-6) quando enfatiza que "O curso (e o estágio) não é práxis do futuro professor, mas é atividade teórica (conhecimento da realidade e definição de finalidades), instrumentalizadora da práxis do futuro professor".

É preciso repensar esta prática levando em consideração o modelo de sua organização nos dias atuais, bem como novas formas de vir a ser constituída, pois durante este processo "[...] o professor em formação vive um momento estratégico em sua vida profissional, vivenciando um verdadeiro ritual de passagem" (MONTEIRO, 2000, p. 141). Por isso, o estágio curricular deve ser compreendido como uma atividade inerente à formação dos futuros professores e deve acontecer, prioritariamente, no contato com a realidade da escola e da sala de aula e na interação com a comunidade escolar, nas escolas de educação básica, espaço primordial de vivência da situação de ensino. Consequentemente, a escola torna-se um local com potencial formativo, necessário e indispensável ao processo de preparação dos futuros professores. Considerar a escola como unidade de formação, responsável pelas práticas de ensino, pode, de acordo com Marcelo Garcia (1999), contribuir para superar o tradicional individualismo que tem caracterizado o processo de aprender a ensinar.

Neste sentido, o estágio configura-se como um momento único para a constituição da docência, conforme assinala Monteiro (2000) ao enfatizar que "[...] organizada em novos moldes, esse momento de formação pode representar uma experiência fundamental na formação profissional dos professores, tendo na Prática de Ensino um momento estratégico” (p. 140). Neste caso, os alunos estagiários que adentram a instituição escolar tem à sua disposição um rol de experiências e vivências que podem, de forma de- 
cisiva, ampliar suas perspectivas de conhecimento da prática profissional. São situações que só são passíveis de serem encontradas no contato direto com a escola e com a sala de aula. Se a formação prática do futuro professor é uma prerrogativa do curso de formação, ela também deve ser para as escolas de uma maneira geral, pois há uma estreita relação entre a formação e a atuação, extensiva aos professores e aos futuros professores, que sinaliza para o seu caráter de complementaridade: não é possível formar um professor sem que o mesmo tenha tido contato com a sua futura profissão da mesma forma que é (ou deveria ser) impossível ingressar na profissão sem que tenha passado por um processo formativo qualificado (FRANÇA, 2005a).

É preciso que a tarefa de formação prática do futuro professor, há tanto atribuída às nossas instituições de educação básica, seja ressignificada. A escola precisa estar ciente de sua tarefa tanto quanto a instituição formadora e precisa, acima de tudo, ver-se como coresponsável neste processo. Ela não é apenas uma agência que acolhe os futuros professores. Ao abrir suas portas, ela cede seu espaço/tempo e é submetida ao olhar ansioso de aprendizes que julgam encontrar naquele espaço respostas para suas indagações e dúvidas suscitadas em seus estudos e reflexões sobre a educação e o ensino.

Por isso, é preciso que haja um esforço no sentido de possibilitar às escolas a compreensão de seu papel frente a essas mudanças na formação dos professores, da mesma forma que deve haver, também, a busca pela sistematização de medidas que venham efetivamente minimizar as críticas a que são submetidos os professores e as escolas quando recebem alunos estagiários. O contato direto e aberto entre os professores da instituição formadora, os alunos estagiários e os professores da escola básica pode ser um caminho promissor para a melhoria desta prática.

Como assinala Cury (2003), as instituições formadoras deverão ser o móvel inicial de construção de uma nova cultura institucional de formação dos docentes que deverão atuar na educação básica. Esta nova cultura institucional assinalada pelo autor refere-se ao modelo de organização da formação de professores que está baseada na articulação entre a formação

Olh@ res, Guarulhos, v. 1, n1, p. 64-89, maio. 2013. 
teórico-prática e o estágio curricular, requerendo dos sistemas de ensino de educação básica uma participação ativa nesse processo, mediada pela construção de parcerias entre instituições formadoras e escolas de educação básica.

Nesta perspectiva, os estudos e pesquisas que discutem esta temática constituem referência para a identificação das concepções e práticas de estágio construídas no contexto dos cursos de formação de professores. Por isso, parece ser importante buscar alguns estudos que mostram como essa questão tem sido tratada.

Inicialmente, os estudos realizados tinham como perspectiva a possibilidade de avaliação de propostas adotadas para os estágios de ensino, visando sua adequação aos objetivos propostos. No início dos anos de 1980 os estudos enfatizavam a relação com o contexto social mais amplo e buscavam analisar a função legalmente proclamada do estágio, assinalando os aspectos impeditivos de uma adequação teoria-prática na realização dessa atividade e, ainda, na análise do estágio enquanto processo, buscando apreender sua função real e avaliar a possibilidade de cumprimento ou não dessa função, na sua relação com as questões da universidade, além de estudos voltados para a identificação da concepção de estágio predominante nos cursos de formação de professores.

Nesse período observa-se uma efervescência na produção sobre essa temática estimulada principalmente pela discussão acerca do papel da Didática na formação dos professores através do movimento "A Didática em questão" (CANDAU, 1982) e pelos eventos realizados na área da Prática de Ensino - os Encontros Nacionais de Prática de Ensino, configurando mais tarde os Encontros Nacionais de Didática e Prática de Ensino - ENDIPE, que têm se constituído em um marco na produção e na discussão da temática da formação de professores. Os trabalhos passaram a abordar temáticas variadas como a contribuição do estágio para a formação de professores, a utilização do estágio como alternativa à formação desses profissionais, a relação teoria-prática na formação dos professores, a possibilidade de aproximação com a realidade escolar, a perspectiva de reflexão sobre a prática docente como elemento integrador das práticas dos professores e, 
mais intensamente, os estudos que avaliavam a importância e o papel do estágio na formação dos professores, com ênfase para a compreensão deste como um componente curricular que deveria estar articulado ao curso.

Moraes (2001), ao analisar os trabalhos sobre estágio apresentados no ENDIPE (edições de 1994 e 1996), assinala que esses estudos enfatizam a busca de alternativas para superar as dificuldades próprias dessa área, bem como da formação de professores. A autora destaca a multiplicidade de enfoques assumidos e identifica quatro concepções presentes nesses estudos: como instância de integração entre universidade e escola; a concepção de estágio como pesquisa sobre a prática docente, ressaltando seu caráter investigativo na prática de ensino; as concepções alternativas de estágio que buscam a integração e/ou interdisciplinaridade das diferentes áreas de saber na perspectiva de superar a dissociação entre teoria e prática e entre ensino e realidade; e, ainda, algumas concepções de estágio com caráter de aplicação do conhecimento, sugerindo que a prática docente deve se caracterizar como a aplicação das regras básicas do conhecimento científico, tal como sugere o modelo da racionalidade técnica.

O trabalho de Almeida e Azzi (2002), apresentado no ENDIPE (edição de 2002), destaca que a concepção de estágio bem como os temas/conteúdos abordados nessas produções evocam questões como a organização dos cursos, as possibilidades, propostas e/ou diretrizes para o estágio. Conforme as autoras, esses trabalhos trazem a discussão sobre o modelo da racionalidade técnica que prevaleceu durante muito tempo fundamentando as propostas de formação de professores e buscam formas de superação desse modelo de formação que se refletia na dicotomia da relação teoria e prática. Nesse sentido, as autoras apontam que a prática da reflexão e a iniciação à pesquisa são as possibilidades apontadas para a formação de um novo profissional (o professor reflexivo). Um avanço observado nesse período refere-se à indicação, presente em muitos estudos, da necessidade de ampliação e de articulação das atividades práticas como forma de favorecer uma maior aproximação à realidade escolar e o conhecimento da realidade educacional pelos futuros professores.

Olh@ res, Guarulhos, v. 1, n1, p. 64-89, maio. 2013. 
A partir dos anos 2000 as produções sobre os estágios de ensino trazem a marca das mudanças ocorridas em nossa realidade, centrando-se em uma concepção de professor como profissional reflexivo, investigador, aberto à colaboração com os pares, entre outros, atribuindo aos estágios de ensino uma tarefa relevante. Os trabalhos que se dedicam a analisar os estágios de ensino acentuam uma concepção dos professores como atores sociais, construtores de saberes profissionais, dando destaque ao papel do estágio nesse contexto, enfatizam os múltiplos espaços de formação, priorizam a articulação entre universidade e escolas e buscam formas alternativas de construção dessa prática, além de apontarem a aproximação entre a universidade e a escola e a importância da articulação teoria e prática na construção do saber profissional.

Em síntese, os estudos iniciais enfatizavam a eficiência e a eficácia dos estágios, abordando a avaliação, adequação de propostas e alcance dos objetivos propostos. Com as mudanças no cenário brasileiro a partir dos anos de 1980, tem-se então uma ampla gama de estudos que passam a enfatizar a necessidade de superação da visão tecnicista na formação do professor, atribuindo aos estágios o papel de elemento articulador da relação teoria e prática.

A partir dos anos de 1990, novos temas foram incorporados à discussão e os estágios de ensino se tornaram referência para os estudos sobre interdisciplinaridade, integração universidade/escola, iniciação à pesquisa/investigação sobre a própria prática, aproximação com a realidade escolar, entre outros, convergindo para reflexões sobre o papel dos professores como profissionais. Esses estudos informam o novo papel do estágio nesse cenário, os espaços de formação, a articulação universidade/escola e a construção de propostas alternativas de estágio. Contudo, os professores, tanto da escola básica quanto os formadores da universidade, estão ausentes nesses estudos. Por isso, torna-se importante retomar os estudos mais recentes que discutem essa temática para evidenciar as concepções e práticas de estágio construídas a partir de diferentes experiências na área de formação de professores. 
Silva e Miranda (2008), em seu estudo, fazem uma discussão sobre os estágios de ensino a partir dos desdobramentos decorrentes das Diretrizes Curriculares para a formação de professores, consideradas pelas autoras como demandas atuais para os profissionais que atuam na área nos cursos de licenciatura, na perspectiva de buscar um novo enfoque e uma nova postura dos profissionais que atuam nesta área: "É preciso entender esse campo de saber enquanto praxis, resultante da inter-relação entre a dimensão teórica e prática da formação" (p. 10).

O estudo de Lima (2012) faz uma interessante revisão dos trabalhos apresentados nas duas edições do Encontro Nacional de Didática e Prática de Ensino - ENDIPE (2008 e 2010), trazendo referenciais para essa discussão, bem como apontando avanços e superações. Tendo como perspectiva a ideia de que a construção e a socialização de conhecimentos sobre os estágios propiciam a elaboração de novas aprendizagens pelos professores formadores e contribuem para a formulação de novas práticas formativas dentro das licenciaturas, a autora destaca a importância da compreensão do espaço/tempo de formação como campo de problematizações que promovam a busca, a descoberta e a construção de conhecimento, por ser neste movimento que o futuro professor articula, de forma consciente, os conteúdos e informações adquiridos ao longo do curso de formação com situações concretas de vivência da profissão.

Entre os avanços apontados por Lima (2012), estão as concepções acerca do estágio como prática pedagógica inserida na prática social, como teoria que ressignifica a prática, como objeto de investigação, de reflexão, de construção e articulação de saberes e conhecimentos, como espaço-tempo de aprendizagem, como oportunidade de experiências pedagógicas, como possibilidade de ensino-aprendizagem da profissão.

Conforme a autora, o estágio é concebido como práxis, com ênfase na relação teoria-prática, na perspectiva de aproximação do estagiário com a realidade educacional, visando apreender a teia das complexas relações que se estabelecem no contexto escolar, como reflexão sobre as diferentes experiências pedagógicas e sobre as posturas próprias da docência na relação educador-educando, visando à aproximação com a futura profissão

Olh@ res, Guarulhos, v. 1, n1, p. 64-89, maio. 2013. 
docente e permitindo ao estagiário analisar, vivenciar e exercitar sua formação profissional de forma crítica e refletida. Essas concepções se organizam através da articulação ensino-pesquisa-extensão, em uma dimensão emancipadora, superando concepções de estágio como momento de avaliação do curso de formação para um fazer derivado de apropriação do conhecimento pedagógico.

Contudo, a ideia que parece prevalecer nesses estudos é a concepção de estágio numa perspectiva de "intervenção" na realidade escolar. Apesar da relevância dada ao diálogo permanente entre escola e instituição formadora, a escola continua sendo vista como o locus de observação das práticas e a instituição formadora como o espaço de "produção de novas práticas". Embora tais estudos enfatizem metodologias alternativas ou advoguem concepções inovadoras acerca do professor, do ensino e aprendizagem e da formação de professores, as ações desencadeadas redundam em alternativas construídas fora do contexto escolar. A escola e a sala de aula tornam-se origem e destino de medidas que são pensadas no âmbito da instituição formadora, provocando uma ruptura na proposta de diálogo e interação que deveriam ser estabelecidas entre as instituições.

Uma forma de enfrentamento desta questão foi apresentada pela experiência do Programa de Residência Pedagógica desenvolvida pela UNIFESP como uma política de formação inicial de docentes capaz de atuar de maneira propositiva em ambientes escolares, gerando aprendizagens e provocando a revisão das práticas de educadores e gestores já profissionais (GIGLIO, 2010). De acordo com a autora, o Programa teve sua implantação precedida de ampla consulta aos gestores e docentes, estabelecendo o diálogo com as redes públicas do município onde está situado o curso de Pedagogia, para identificar, junto aos gestores de sistemas e de escolas públicas, as demandas relativas à formação inicial de professores e, junto aos docentes, as demandas de formação continuada originadas de suas práticas pedagógicas atuais.

Conforme Giglio et al. (2011), as escolas e seus profissionais reconheceram a importância da aprendizagem prática para a atuação profissional, a responsabilidade e a contribuição que podem dar a essa formação, explicita- 
ram expectativas claras de uma participação ativa dos residentes e ressaltaram a necessidade de haver reciprocidade entre a universidade e a escola, apresentando ainda preocupação quanto a aspectos éticos, de respeito às instituições escolares e a seus profissionais.

Como se pode notar, as escolas e seus atores tem algo a dizer sobre as atividades de estágios que se desenvolvem no seu espaço institucional. Essa possibilidade precisa ser garantida no momento de construção de propostas que articulam o processo de formação dos futuros professores tendo a escola e seus profissionais como colaboradores. Conforme a autora, é necessário compreender como as ações inerentes a este processo podem e devem ser organizadas visando a colaboração “[...] para transformar os estágios tradicionais numa oportunidade de renovação da formação inicial e contínua de docentes e gestores escolares e no estabelecimento de novas relações entre as escolas públicas e a universidade" (GIGLIO et al., 2011, p. 39). Essa discussão está apenas se iniciando.

Neste sentido, parece ser pertinente olhar para a atividade realizada pelo professor formador da escola de educação básica para evidenciar as condições de trabalho enfrentadas por esses profissionais e as possibilidades de construção de uma proposta colaborativa entre universidade e escola para a preparação dos futuros professores.

\section{A atividade de supervisão do estágio e os professores formadores da educação básica}

Fazer referência à atividade dos professores formadores da educação básica é falar da tarefa de supervisão e acompanhamento que esses profissionais desempenham quando recebem alunos estagiários dos cursos de formação de professores em suas salas de aula. Em tese, o professor formador é aquele profissional experiente que assume a responsabilidade de conduzir o futuro professor nas inserções pelo ensino, em sua sala de aula na escola básica, garantindo que o estágio se configure como tempo de aprendizagem, conforme dispõe o Parecer CNE n’ 28/2001, e que supõe “[...] uma relação 
pedagógica entre alguém que já é um profissional reconhecido em um ambiente institucional de trabalho e um aluno estagiário" (BRASIL, 2001). Portanto, essa discussão demanda algumas reflexões acerca desta prática em função das limitações e dificuldades enfrentadas na sua realização. Entre elas está o desconhecimento dos professores sobre seu papel formativo (FRANÇA, 2005a) e, igualmente, o não reconhecimento, pela escola, de sua responsabilidade formativa. Também, devem ser levados em consideração aspectos como a interação entre a universidade e a escola (FRANÇA, 2005b) que afetam diretamente a qualidade desta orientação, as condições de trabalho dos professores e o envolvimento dos alunos estagiários com sua própria formação (interesse, disponibilidade de tempo, etc).

Apesar das limitações acima apontadas, a tarefa de acompanhamento e supervisão do estagiário, realizada pelos professores em exercício, é uma etapa imprescindível ao processo de aprender a ensinar dos futuros professores. Por isso, ela precisa ser pensada como uma tarefa inerente à docência, que perpassa todo o processo formativo e que requer $o$ envolvimento do curso como um todo para que as conexões possam ser estabelecidas adequadamente, facilitando as relações entre o conhecimento e a prática profissional. O processo de aprender a ensinar não pode prescindir dessa etapa formativa da mesma forma que não pode ou não deve desconsiderar essa oportunidade privilegiada de contato e aprendizagem do ofício docente.

Entretanto, esta é uma tarefa que parece não ser muito evidente para os professores que recebem os alunos estagiários, ou seja, muitas vezes eles desconhecem seu papel formativo frente aos futuros professores que adentram suas salas de aula. Esta é uma situação repleta de ambiguidades e contradições que acentuam, cada vez mais, os problemas enfrentados pelos professores e pelos futuros professores no processo de aprendizagem do fazer docente.

Os professores que recebem os alunos estagiários, muitas vezes, atuam no limite da concessão do espaço da sala de aula para que estes possam cumprir seu estágio, sem ter tido a oportunidade de compartilhar suas perspectivas de ensino e profissionais, num contex to em que as atividades desenvolvidas 
parecem compor um ritual que não foi estabelecido entre as partes. Esse desconhecimento tem se constituído em um problema a ser enfrentado continuamente no processo de estágio na escola, cujo alcance parece estar ausente das discussões sobre a preparação dos futuros professores. Implica olhar para questões como os critérios usados no encaminhamento dos futuros professores para as escolas, a seleção das escolas, a disponibilidade dos professores para cumprir esta tarefa e, também, a qualidade desta orientação, entre outros.

Num contexto em que a própria organização das atividades deste componente curricular ainda se faz de forma fragmentada, com poucas indicações acerca dos aspectos a serem considerados no processo formativo, pensar na qualidade e na consistência das orientações parece destoar da realidade encontrada nos cursos de formação de professores. Por isso, assumir a tarefa de orientação aos alunos estagiários como professor formador, conforme as indicações das diretrizes de formação dos professores, não é uma tarefa simples. É preciso ir além e delimitar, com mais clareza, quais tarefas são esperadas deste profissional e em quais condições elas são possíveis de serem realizadas.

Esta é, na verdade, uma questão que precisa ser aprofundada nas discussões sobre a temática, pois a mediação que se faz entre o conhecimento teóricoprático e a prática docente depende de e supõe uma tarefa específica que é inerente a esses profissionais. Sem a participação efetiva dos professores, corre-se o risco de deixar aos alunos estagiários, apenas, a tarefa de estabelecer as relações e conexões entre o conhecimento e a sua futura prática profissional.

Há que se ressaltar, portanto, a aproximação à prática docente como uma tarefa que precisa ser direcionada para o conhecimento do processo de ensino que aí ocorre, buscando conhecer suas dimensões e necessidades, pois conforme aponta Marcelo Garcia (1999), esta etapa deve favorecer a compreensão da escola como um organismo em desenvolvimento (caracterizada por uma determinada cultura, clima organizacional, estrutura de funcionamento), deve levar à compreensão dos problemas de ensino como problemas curriculares (planificação, níveis de interpretação do currí- 
culo pelos professores, contato com materiais curriculares e com inovações) e, principalmente, enfatizar a observação do ensino (articulação entre o ensino e o projeto curricular, fixando-se na análise do ensino em oposição à análise do professor), além de se constituir em um momento de socialização (aprender a se comportar como professor).

Deste ponto de vista, esta atividade é essencial e precisa ser realizada continuamente, pois que esta aprendizagem se faz na interação entre os professores e os futuros professores, num processo permanente de conhecimento e reconhecimento do fazer docente, em que ambos partilham formas de ser e de estar na profissão, construídas no dia-a-dia da sala de aula e no contato direto com os alunos em seu processo de aprendizagem. Portanto, este é um aspecto que está implicado diretamente nas decisões que são tomadas continuamente durante a realização do estágio de ensino. Decisões que passam pela construção coletiva da proposta de estágio e pela efetivação das atividades dela decorrentes na escola. Por ser uma atividade que envolve as duas instituições, é preciso que ambas participem ativamente de sua elaboração. Assim sendo, não cabem neste processo nem o desconhecimento de tarefas e, tampouco, a ausência de atribuições específicas para os profissionais que irão assumir diretamente a responsabilidade pelo processo de supervisão dos estágios de ensino.

Isto implica, necessariamente, uma maior compreensão por parte dos profissionais, tanto da escola quanto da instituição formadora, acerca de seu papel como agentes formadores. Da mesma forma, requer compromisso ético e competência no desenvolvimento desta tarefa, pois é preciso avançar na compreensão desta atividade para que seja possível estabelecer novos parâmetros para a produção de práticas comprometidas com uma formação qualitativamente melhor para todos os professores.

Esta tarefa envolve também a escola. Esta carrega consigo a responsabilidade de oferecer condições para que os futuros professores possam interagir com a situação de ensino e, principalmente, possam apropriar-se de um saber-fazer advindo da experiência coletiva dos professores. Por isso, a escola deve ser vista em sua tarefa formativa, ou seja, deve propiciar condições para que os futuros professores possam com- 
preender sua função social em meio a tantas outras atividades que lhe são designadas cotidianamente.

Para que tais atividades possam se efetivar, necessário se faz estabelecer parcerias entre a universidade e a escola, visando à construção de propostas que promovam a qualidade da formação e atuação docente. Esta indicação demanda uma maior abertura por parte de ambas as instituições no sentido de propiciar uma ação colaborativa que defina as bases para a realização dos estágios. Estes não podem ser pensados apenas no âmbito da universidade.

É preciso que a escola e, principalmente, os professores possam e saibam dizer quais as necessidades postas pela realidade de ensino e que elementos concorrem para a sua consecução, tendo em vista a aprendizagem dos futuros professores. Tal medida deve vir acompanhada de outra ainda mais importante, ou seja, o conhecimento das reais condições de trabalho dos professores que atuam na escola de educação básica (salário, tempo disponível, salas superlotadas, desvalorização profissional, críticas exacerbadas dos estagiários) e de como isso pode afetar diretamente o trabalho docente. Isto porque, mais do que consentir que o aluno estagiário permaneça observando a aula e o trabalho do professor, é preciso demonstrar disposição para introduzir esse aluno nas atividades que lhes são próprias. Significa aceitar e querer ensinar algo que já domina e que faz e refaz continuamente. Significa, também, abrir portas, mostrar caminhos, dialogar, superar os erros, compartilhar os acertos...

E essa tarefa não é tão simples. É preciso abrir mão de uma rotina estabelecida para construir novas práticas que incluam os novos aprendizes do ofício. Construir toma o sentido de superação das práticas estabelecidas em função da necessidade de significar para o futuro professor esse saber fazer docente e, ao mesmo tempo, ressignificar para si próprio uma ação que se faz e se refaz continuamente. É um contínuo, em que o conhecimento se faz experiência e a experiência se faz conhecimento, mediado pelo trabalho docente. É o professor que constrói a sua práxis e o futuro professor que aprende o significado dessa práxis do professor em exercício, para tomá-la como referência para a construção de sua prática, ainda que provisória.

Olh@ res, Guarulhos, v. 1, n1, p. 64-89, maio. 2013. 
Entretanto, em que consiste a atividade de supervisão dos estágios de ensino? Normalmente, o professor da sala se encarrega de definir, ele próprio, o que deve ou não ser feito, o como fazê-lo e, principalmente, determinar o rumo que essa ação deverá seguir. Ele resgata, então, as etapas de observação e participação como elementos constituintes dessa atividade, sem levar em consideração que o próprio estagiário, em muitas situações, vem com o propósito de primeiro observar o professor e depois participar das atividades desenvolvidas em sala. Porém, durante o tempo que esses alunos permanecem em suas salas, muitas vezes eles não saem da condição de observadores.

Esta situação parece caracterizar, por um lado, as concepções dos docentes que veem o estágio como observação de modelos, como tem sido até recentemente, quando se dispõem a desempenhar a tarefa de supervisão sem, contudo, provocar interrupção ou transtornos em sua prática docente. Por outro lado, pode estar sinalizando para a questão da disponibilidade (de tempo, de espaço, conhecimento disponível, entre outros) para inserir o futuro professor nas primeiras experiências com o ensino.

Sendo assim, é preciso abordar a questão da responsabilidade formativa do professor da escola básica. Essa questão, especialmente, não tem sido muito discutida em nossa realidade. Os professores que recebem os alunos estagiários não têm muita clareza sobre o que fazer com os alunos - futuros professores. Nesse caso, eles simplesmente aceitam os estagiários, mas não assumem sua responsabilidade formativa nesse processo. Talvez porque desconheçam tal responsabilidade. Talvez porque não se dispõem a realizar tal tarefa, por se constituir em uma tarefa a mais na sua tão desvalorizada função docente.

Fávero (1993), no início dos anos de 1990, fez referência ao estágio como um verdadeiro nó górdio, mostrando o descompasso entre o discurso que afirmava ser o estágio o elemento de integração entre teoria e prática, mas que na realidade continuava sendo um mecanismo de ajuste na defasagem entre elementos teóricos e trabalhos práticos.

Hoje, a despeito de todos os problemas já há muito denunciados, o nó górdio do estágio parece ser a responsabilização da escola pela formação 
prática dos futuros professores sem que a mesma tenha tido a oportunidade de discutir esta questão de forma abrangente e, consequentemente, o desconhecimento por parte dos professores formadores da escola básica sobre sua responsabilidade formativa.

Até então, o papel do professor da escola básica se restringia em ceder o espaço da sua sala de aula para os estagiários, para que ali pudessem fazer suas observações e dar sua aula de regência, em cumprimento às exigências do curso de formação. Agora, mediante as mudanças introduzidas na formação de professores, ele deve compartilhar o processo formativo dos futuros professores sem que ao menos tenha sido ouvido nesse processo. São medidas adotadas de cima para baixo e que caem exatamente nas mãos dos professores da escola básica sem maiores esclarecimentos a respeito.

Por isso, mais do que aceitar, é preciso querer ensinar os futuros professores a lidar com o ensino desde as primeiras inserções na sala de aula. É preciso, também, criar mecanismos que permitam que esses profissionais destinem um tempo de sua atividade profissional a essa tarefa particularmente importante para a formação dos futuros professores.

Neste sentido, a formação prática deve ser redimensionada para atender as necessidades formativas dos futuros professores num contexto de mudança permanente em que não cabe mais a fragmentação das atividades docentes. Como assinala Azzi (1999), o trabalho docente é um trabalho inteiro e é como tal que precisa ser compreendido pelos profissionais responsáveis por essa formação.

No que se refere ao papel do professor orientador de estágio na instituição formadora, é preciso ter cuidado e discernimento quanto ao alcance da sua tarefa. A orientação de estágio não pode colidir com a atuação do professor da escola básica em seu campo próprio de trabalho: a sala de aula. É o professor da sala que está capacitado a atuar neste espaço; é ele quem domina os conhecimentos necessários ao bom andamento do ensino na sua sala de aula; é ele quem conhece cada criança que tem sob sua responsabilidade e a quem deve fazer aprender.

A tarefa de orientação dos estágios de ensino pelos professores da instituição formadora precisa, então, estar restrita ao espaço que lhe é

Olh@ res, Guarulhos, v. 1, n1, p. 64-89, maio. 2013. 
próprio, qual seja, o de orientar e encaminhar os futuros professores para o estágio a fim de que se efetive o contato com a realidade da escola e da sala de aula e possa, de fato, vir a conhecer esse espaço de atuação de forma direta e realista. E, a partir daí, coordenar suas ações, dando o suporte necessário para que os futuros professores tenham conhecimento e condições de interagir com os professores, com os alunos, com a comunidade, com os pais, enfim, com a escola, e possam, de fato, desempenhar, sob a supervisão e acompanhamento do professor formador, as atividades inerentes ao ensino, de forma a cumprir adequadamente a finalidade do estágio que é a aprendizagem da docência.

Ao professor formador, ou o professor supervisor de estágio, cabe a outra parte dessa tarefa: a inserção do futuro professor na realidade da escola e da sala de aula, permitindo que exerça, sob sua supervisão, progressivamente, o ato de ensinar em suas variadas dimensões ou facetas: coordenar a sala, gerir o tempo de aprendizagem, gerir a matéria, etc. Essa tarefa, específica do professor da escola básica, não pode ser realizada pelos professores orientadores da instituição formadora, no espaço da sala de aula deste último, passando por cima de sua autoridade e de sua autonomia, como professor responsável por este espaço. É preciso reconhecer esses limites e atuar conjuntamente, pois, a situação inversa também não ocorreria.

Reconhecer os espaços de atuação e buscar atuar coletivamente na preparação dos futuros professores parece, até este momento, ser a postura adequada a ser tomada por ambos nesse processo. É preciso reconhecer as tarefas específicas, mas, acima de tudo, é importante compartilhar as responsabilidades no limite mesmo de intervenção de cada um, criando assim uma rede de relações que possa efetivamente dar a sustentação aos futuros professores nesses primeiros passos rumo a sua preparação profissional.

Aqui talvez resida uma questão que até agora não tem sido muito evidente. A necessidade de o professor formador compreender a importância de sua participação nesse processo, porque só ele pode favorecer esta aprendizagem. E também, a importância de se conquistar espaço na carga horária deste profissional para que possa, de fato, desempenhar esta função 
reconhecidamente e possa ter garantias de que esta não será apenas mais uma tarefa junto a tantas outras que desempenha sem qualquer remuneração ou reconhecimento. É preciso criar um mecanismo que possa garantir a todos os professores dispostos a exercer essa tarefa o tempo e as condições mínimas para que possam, efetivamente, orientar os futuros professores nesses primeiros contatos com a docência.

Seria a institucionalização do papel do professor formador nas escolas de educação básica para atender aos alunos estagiários e para prestar-lhes um acompanhamento pormenorizado nesse processo. Isso poderia ser feito através de convênios que viessem garantir uma bolsa de estudo para que esses professores pudessem ter tempo disponível para se atualizarem, mantendo o vínculo com a instituição formadora, qualificando-se e requalificando-se continuamente para exercer a tarefa de supervisão dos futuros professores. Esse contato permanente levaria a um aprofundamento das relações entre os profissionais envolvidos com a preparação profissional dos futuros professores no sentido de definição de propostas conjuntas que pudessem atender amplamente suas necessidades formativas nesse contato com a escola básica.

Um fórum de discussão permanente onde alunos estagiários, professores formadores e professores orientadores de estágio estivessem continuamente revendo as condições de realização do estágio e de atuação do futuro professor, além de um espaço de reflexão coletiva em que os estagiários pudessem contribuir com a escola propondo o estudo permanente de questões ligadas ao ensino e à educação, sob a orientação estreita dos professores da instituição formadora.

Esse reconhecimento ao trabalho efetivado pelos professores formadores poderá garantir que bons e experientes professores abram, de fato, as portas de suas salas de aula e queiram, antes mesmo de aceitar alunos em suas salas de aula, orientar e ensinar esses futuros professores, acompanhando-os em suas inserções pela docência, de forma que possam efetivamente constituir-se professores competentes e compromissados com a qualidade da educação em nossas escolas.

Olh@ res, Guarulhos, v. 1, n1, p. 64-89, maio. 2013. 


\section{Algumas considerações a título de conclusão}

Discutir sobre o papel dos professores formadores na condução das atividades de estágio junto aos alunos estagiários no interior da escola básica é temática recente e ainda não tem merecido um aprofundamento dos estudos para explicitar aspectos importantes dessa ação que permanecem silenciados.

Ainda assim, é importante assinalar que os professores da escola básica não são vistos aqui como redentores de todas as mazelas educacionais. A importância dada a estes profissionais está relacionada à valorização e ao reconhecimento de seu trabalho na construção de propostas alternativas que garantam melhores condições de formação/atuação no contexto da educação básica para nossos futuros professores. Mesmo porque, embora criticados em suas ações, são esses profissionais que são chamados a dar conta desta preparação ao se dispor a receber, acompanhar e supervisionar os futuros professores em suas inserções pela escola e pela sala de aula.

Por isso, parece ser interessante, neste momento, indicar a necessidade de aprofundamento desta temática mediante a abordagem de questões que dizem respeito à atuação dos professores formadores: Como se dá a preparação formal desses professores? Quem são? Qual a sua formação? Que conhecimentos dominam sobre o processo de supervisão dos estágios de ensino?

À medida que novos conhecimentos sobre essa atividade forem trazidos para o debate, será possível evidenciar a importância do estágio ao favorecer o contato com o ensino. Isto porque o ensino se constitui no objeto de trabalho de professores e futuros professores e, por sua vez, ocorre no contexto da organização escolar e se desenvolve de forma singular, mas não menos determinado pelas condições históricas dadas: possibilidades concretas do exercício da docência, condições de trabalho e salário, adversidades, limitações e desafios postos pela realidade social. E, ainda, é preciso reconhecer a necessidade de envolvimento dos futuros professores com a efetivação dos estágios de ensino, pois sem este envolvimento tais atividades servirão apenas para cumprir os rituais impostos pelo curso de 
formação de professores, não guardando nenhuma relação com o processo de aprender a ensinar.

Neste caso, é preciso considerar a disponibilidade de tempo dos alunos estagiários para o cumprimento das atividades relacionadas com o estágio, a disposição para realizar todas as solicitações pertinentes ao curso e, também, a manifestação de interesse por parte desses futuros professores em realizar as atividades designadas para este fim.

Para que isto ocorra, os professores formadores devem ter clareza da tarefa que desempenham ao colaborar com a formação prática dos futuros professores, bem como participar ativamente do processo de construção de propostas de estágio que favoreçam a interação de professores e futuros professores, visando o processo de aprender a ensinar.

Neste contexto, é necessário ressaltar todos estes aspectos envolvidos no trabalho do professor que não podem e não devem ser desconsiderados, correndo-se o risco de reduzir à esfera da sala de aula, apenas, uma temática tão ampla e que ainda não está decisivamente estabelecida na pauta das discussões educacionais. Neste caso, especificamente, é preciso e urgente o debate em todos os cursos de licenciatura para que os estágios curriculares possam ser ressignificados, ou conforme aponta Silvestre (2011), os estudos sobre esta temática precisam avançar no sentido de "[...] apontar o porquê de sua permanência nos cursos, qual a sua função na formação profissional dos professores e que modelo de supervisão é o mais adequado." (SILVESTRE, 2011, p. 167 - grifo da autora).

Por isso, o grande desafio do estágio é, conforme assinalam Lima e Aroeira (2011), constituir-se como espaço de aprendizagem que leva a refazer continuamente a prática e a descobrir novos jeitos de compreender o fazer pedagógico e de conviver com ele, pois “[...] o estágio é um espaço privilegiado de práxis, um lugar de partida e de chegada para a nossa vida profissional" (p. 131).

Por outro lado, as diferentes concepções e práticas de estágio construídas a partir das diversas experiências na área de formação de professores tem mostrado um avanço dessa área de investigação muito oportuna quando se pensa a formação de professores. Contudo, é importante destacar também a

Olh@ res, Guarulhos, v. 1, n1, p. 64-89, maio. 2013. 
necessária ampliação do debate sobre essa temática a partir das mudanças trazidas pelas Diretrizes Curriculares do curso de Pedagogia, numa clara referência à experiência construída mediante a criação do Programa de Residência Pedagógica (GIGLIO et al., 2011), para explicitar novas formas de organização desse componente curricular que favoreça a explicitação das tensões e dilemas ainda não resolvidos, conforme assinala Pimenta (2011, p. 10) ao destacar "[...] que o estágio constitui um campo de conhecimento que se produz na interação entre cursos de formação e o campo social no qual se desenvolvem as atividades educativas, entre as quais a de ensinar, própria dos profissionais professores". Esse parece ser o desafio.

Olh@res, Guarulhos, v. 1, n1, p. 64-89, maio. 2013. 


\section{Referências Bibliográficas}

ALMEIDA, J. S. Estágio Supervisionado em Prática de Ensino - relevância para a formação ou mera atividade curricular? Revista ANDE, ano 13, nº. 20, p. 39-42, 1994.

ALMEIDA, P. C. A.; AZZI, R. G. Prática de Ensino/Estágio Supervisionado: uma análise das produções brasileiras. In: ENCONTRO NACIONAL DE DIDÁTICA E PRÁTICA DE ENSINO, 11, 2002, Goiânia. Igualdade e diversidade na Educação - Anais do XI Encontro de Didática e Prática de Ensino. Rio de Janeiro: Multipolo, 2002, p. 01-08. 1 CD-Rom.

AZZI, S. Trabalho Docente: autonomia didática e construção do saber pedagógico. In: PIMENTA, S. G. (Org.) Saberes pedagógicos e atividade docente. São Paulo: Cortez, 1999. CANDAU, V. M. (Org.). A Didática em questão. Petrópolis: Vozes, 1982.

BRASIL. Conselho Federal de Educação. Parecer 292/62. Revista Documenta, nº11, ano 1962.

Parecer CNE/CP n 28, de 2001. Diário Oficial da União, Brasília, 18/01/2002. Seção 1, p. 31.

CURY, C. R. J. Estágio Supervisionado na formação docente. In: LISITA, V. M. S. S.; SOUZA, L. F. E. C. P. Políticas educacionais, práticas escolares e alternativas de inclusão escolar. Rio de Janeiro: DP \&A, 2003.

FÁVERO, M. L. A. Universidade e estágio curricular: subsídios para uma discussão. In: ALVES, N. (Org.). Formação de Professores: pensar e fazer. 2.ed. São Paulo: Cortez, 1993.

FRANÇA, D. S. A constituição da docência: o que se ensina e o que se aprende sobre o fazer docente na relação entre professoras em exercício e futuras professoras. Araraquara, 2005a. Tese (Doutorado em Educação). Universidade Estadual Paulista "Júlio de Mesquita Filho".

Formação de Professores: a parceria Escola-Universidade e os estágios de ensino.

UNIRevista, vol. 1, n 1, São Leopoldo/RS: Unisinos, 2005b, p. 01-14. Revista Eletrônica disponível no site: <http:/www.unisinos.br/publicações_cientificas/>

GIGLIO, C. M. B. Residência Pedagógica como diálogo permanente entre a formação inicial e continuada de professores. In: DALBEN, A. I. L. F. (Org.). Convergências e tendências no campo da formação e do trabalho docente. Belo Horizonte: Autêntica, 2010.

GIGLIO, C. M. B. et al. Residência Pedagógica: diálogo permanente entre a formação inicial e a formação contínua de professores e pedagogos. In: GOMES, M. O. (Org.). Estágios na

Olh@res, Guarulhos, v. 1, n1, p. 64-89, maio. 2013. 
formação de professores: possibilidades formativas entre ensino, pesquisa e extensão. São Paulo: Edições Loyola, 2011.

LIMA, M. S. L.; AROEIRA, K. P. O estágio curricular em colaboração, a reflexão e o registro reflexivo dos estagiários: um diálogo entre a universidade e a escola. In: GOMES, M. O. (Org.). Estágios na formação de professores: possibilidades formativas entre ensino, pesquisa e extensão. São Paulo: Edições Loyola, 2011.

LIMA, M. S. L. Estágio e aprendizagem da profissão docente. Brasília: Líber Livro, 2012. MARCELO GARCIA, C. Formação de professores: por uma mudança educativa. Porto: Porto Editora, 1999.

MONTEIRO, A. M. A Prática de Ensino e a produção de saberes na escola. In CANDAU, V. M. (Org.). Didática, currículo e saberes escolares. Rio de Janeiro: DP\&A, 2000.

MORAES, S. P. G. Do debate no interior da área de Prática de Ensino às questões centrais do processo de formação de professores. In: REUNIÃO ANUAL DA ASSOCIAÇÃO NACIONAL DE PESQUISA E PÓS-GRADUAÇÃO EM EDUCAÇÃO, 24, 2001, Caxambu. Intelectuais, conhecimento e espaço público - Anais da 24 ${ }^{\mathrm{a}}$ Reunião Anual da ANPEd. Rio de Janeiro: Associação Nacional de Pesquisa e Pós-Graduação em Educação, 2001, p. 01-18. 1 CD-Rom.

PIMENTA, S. G. O estágio na formação de professores. São Paulo: Cortez, 1994.

Prefácio. In: GOMES, M. O. (Org.). Estágios na formação de professores: possibilidades formativas entre ensino, pesquisa e extensão. São Paulo: Edições Loyola, 2011.

SILVESTRE, M. A. Sentidos e significados dos estágios curriculares obrigatórios: a fala do sujeito aprendente. In: GOMES, M. O. (Org.). Estágios na formação de professores: possibilidades formativas entre ensino, pesquisa e extensão. São Paulo: Edições Loyola, 2011. 